\title{
Aprendizagem de Conceitos Físicos a Partir da Construção de uma Mini Geladeira de Pastilha Peltier
}

\section{Learning physical concepts from the construction of a Peltier device mini} fridge

\author{
R. S. Moraes ${ }^{1}$, A. P. GUILHERME ${ }^{* 2}$ \\ ${ }^{1}$ Secretaria de Estado de Educação e Qualidade do Ensino do Amazonas. \\ ${ }^{2}$ Universidade Federal do Amazonas.
}

\begin{abstract}
Resumo
Em um cenário educacional composto de muitas dificuldades no que se diz respeito ao ensino/aprendizagem na disciplina de Física, a utilização de metodologias inovadoras é uma tendência a ser analisada para se obter um maior rendimento na disciplina. O presente trabalho tem por objetivo descrever como a cultura maker pode auxiliar no processo de ensino e aprendizagem propondo a construção de uma mini-geladeira de pastilha peltier a partir da perspectiva maker, $e$ no momento da construção e funcionamento desta, identificar os principais conceitos físicos que podem ser desenvolvidos com os alunos.
\end{abstract}

Palavras-chave: Cultura Maker. Pastilha Peltier. Construcionismo.

*adrianopgpg@gmail.com 


\begin{abstract}
In an educational scenario composed of many difficulties, which concerns the teaching/ learning of the discipline of Physics, the use of innovative methodologies is a tendency to be analyzed to obtain a higher performance in the discipline. The present work aims to describe how maker culture can assist in the teaching and learning process, proposing a construction of a peltier tablet mini fridge from the maker perspective, and no moment of construction and execution in this way, identifying the main methods used that can be developed with students.
\end{abstract}

Keywords: maker culture. Peltier device. Construcionism.

\title{
I. INTRODUÇÃO
}

A sociedade passa por um grande processo de inovação e transformação, e nesse processo podem se destacar os indivíduos que aperfeiçoam a habilidade de criar e de adaptar-se às transformações (NONAKA; TAKEUCHI, 1997).

A Cultura Maker vem se destacando nesse cenário de inovações. O "pôr a mão na massa", junto ao "faça você mesmo" (do it yourself - DIY) atrai cada vez mais indivíduos interessados em criar e compartilhar suas próprias invenções, sejam elas físicas ou digitais, principalmente devido à sua forma de expressão criativa e por ser algo "comunitário". Há um grande crescimento dessa prática, tanto em ambientes informais (em casa, em centros comunitários, etc), como em ambientes formais (universidades e escolas). A aprendizagem baseada no fazer ou construir já faz parte da educação há algum tempo. Nesse sentido, Seymour Papert é considerado o pai do movimento maker na educação, ao passo que é o principal responsável por desenvolver a teoria do construcionismo, que aborda o aprender fazendo e o seu compartilhamento como forma de aprendizado. A abordagem construcionista instiga habilidades e competências por meio de atividades em que o aprendiz, por meio do fazer, constrói algo de seu interesse e para o qual está motivado (PAPERT, 1980). Nesse contexto, o movimento maker vem sendo considerado como o próximo salto educacional e tecnológico, substituindo as aulas tradicionais, que priorizam em certo ponto as metodologias expositivas consideradas repetitivas e "chatas" pela maioria dos estudantes (BROCKVELD; TEIXEIRA; SILVA, 2017).

Partindo desse pressuposto, o enfoque desse trabalho está voltado a como a cultura maker pode se aliar à educação para auxiliar a aprendizagem de conceitos físicos. Através da construção de uma mini-geladeira de pastilha peltier, pretende-se inserir um pouco dessa cultura maker dentro do ambiente escolar. Propondo uma abordagem didática, é possível propiciar a compreensão dos principais conceitos físicos envolvidos na construção e funcionamento da mini-geladeira. Diversos conceitos físicos podem ser aprendidos por alunos envolvidos num processo como este, tais como corrente elétrica, voltagem, potência, isolamento, condutibilidade, formas de transmissão de calor, temperatura, mudança de fase (condensação), radiação térmica, etc. 


\section{CULTURA MAKER E SEU USO NO ENSINO}

“O movimento maker é uma extensão tecnológica da cultura do 'Faça você mesmo', que estimula as pessoas comuns a construírem, modificarem, consertarem e fabricarem os próprios objetos, com as próprias mãos. Isso gera uma mudança na forma de pensar [...] Práticas de impressão 3D e 4D, cortadoras a laser, robótica, arduíno, entre outras, incentivam uma abordagem criativa, interativa e proativa de aprendizagem em jovens e crianças, gerando um modelo mental de resolução de problemas do cotidiano. É o famoso 'pôr a mão na massa'." (Silveira, 2016)

A Cultura maker é influenciada pela cultura do faça você mesmo, Do It Yourself (ou simplesmente DIY) ou faça com os outros (do it with others = Diwo), que consiste na formação de grupos de pessoas com interesses similares, que buscam compartilhar ideias para a melhoria e a troca de conhecimentos sobre um produto qualquer, no sentido de buscar sua melhora. Esta cultura estabelece que qualquer indivíduo, mesmo que não seja um especialista, pode vir a construir, restaurar, transformar e fabricar por conta própria os mais diversos tipos de objetos e projetos, por vezes se utilizando até de materiais de baixo custo. Ou seja, qualquer um pode pôr a "mão na massa" e fazer suas próprias invenções, ou melhorar o que já existe. Além disso, estimula dentro do campo criacional, a invenção de muitas tendências e objetos que venham a ser de utilidade para muitas outras pessoas. Para Halverson e Sheridan (2014), "o movimento maker refere-se ao número crescente de pessoas engajadas na produção criativa de artefatos em suas vidas diárias e que compartilham seus processos e produtos com outras pessoas em fóruns físicos e digitais".

O movimento maker está presente e vem crescendo constantemente em outros campos da sociedade, como por exemplo a educação. Dentro da cultura maker encontramos autonomia, tecnologia e liberdade de criação para estabelecer um ambiente de experimental que seja propício ao aprendizado. Na prática, um indivíduo maker muda a realidade através de uma contribuição autoral. Ou seja, ele usa sua capacidade de criação para transformar aquilo que era uma ideia em algo palpável. Sendo assim, se trata de mudar a própria concepção de escola. Hoje o conhecimento é apresentado de forma pronta e estruturada, quase como se tivesse sido fabricado. O estudante vai à escola, consome as aulas sem muitas vezes compreender como certos conceitos foram criados, com foco apenas no conteúdo que cada disciplina tem a transmitir. É necessário que se quebre esse paradigma e estimule o aluno a formular teorias construindo-as por meio da experimentação. Neste sentido, a educação associada ao movimento maker é diferenciada em relação às aulas tradicionais porque o aluno adquire ferramentas para compreender e aprimorar os conhecimentos recebidos nas aulas expositivas, ou seja, o estudante aprende a aprender.

Especificamente para a nossa proposta, pensou-se na construção de uma mini-geladeira na perspectiva da cultura maker. A ideia é que alunos que venham a desenvolver um projeto semelhante aprendam alguns conceitos físicos importantes, onde destacamos:

\section{- Fenômenos Termoelétricos}

Os fenômenos termoelétricos associam o fluxo de calor com corrente elétrica, com o objetivo de gerar energia elétrica ou térmica. Um dispositivo termoelétrico é utilizado para 
geração de energia. Quando existe uma diferença de temperatura (gradiente de temperatura) entre seus lados frio e quente, este dispositivo cria uma corrente elétrica. "Um dispositivo termoelétrico também é utilizado para geração de energia térmica, onde a direção do fluxo de aquecimento é determinada pelo sentido da passagem da corrente elétrica" (MONTEIRO, 2016).

\section{- Efeito Peltier}

O efeito de Peltier, descoberto em 1834, é um fenômeno termoelétrico que produz um gradiente de temperatura ( $\mathrm{Tq}$ e $\mathrm{Tf}$ ) quando se aplica uma tensão em um circuito elétrico fechado que gera uma corrente que atravessa um corpo formado por uma junção de condutores ou semicondutores distintos, onde dependendo do sentido de passagem da corrente elétrica, uma das junções absorve o calor e a outra o libera (DANVIC, 2020). É um conceito razoavelmente avançado para o ensino médio, sendo mais adequado seu detalhamento para alunos de graduação.

As Placas de efeito Peltier, também conhecidas como pastilhas termoelétricas utilizam o efeito de aquecer ou esfriar quando se passa corrente elétrica contínua por dois condutores. A pastilha Peltier é a maneira mais prática de se utilizar o efeito peltier como refrigerador em larga escala, e consiste num arranjo de pequenos blocos de telureto de bismuto - Bi2Te3 dopados tipo $\mathrm{N}$ e tipo P como na Figura 1 abaixo:

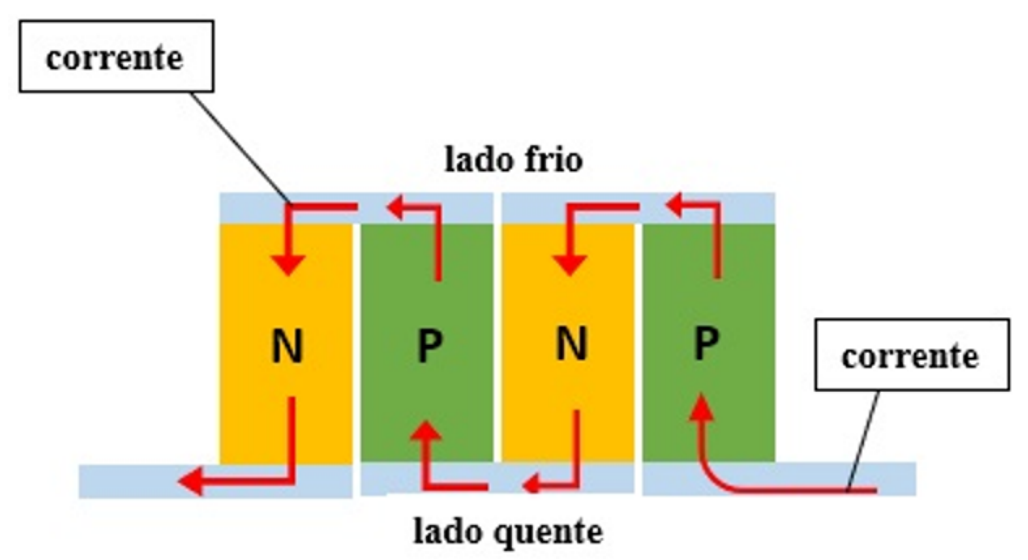

Figura 1: Semicondutores do tipo N e P no funcionamento da pastilha peltier.

Essa série de elementos é soldada entre duas placas cerâmicas, eletricamente em série e termicamente em paralelo. Quando uma corrente DC passa por um ou mais pares de elementos de tipo-n a tipo-p, há uma redução na temperatura da junta (lado frio) resultando em uma absorção do calor do ambiente. Este calor é transferido pela pastilha por transporte de elétrons e emitido no outro lado (quente) via elétrons que movem de um estado alto para um estado baixo (FERNANDES, 2010) conforme Figura 2. 


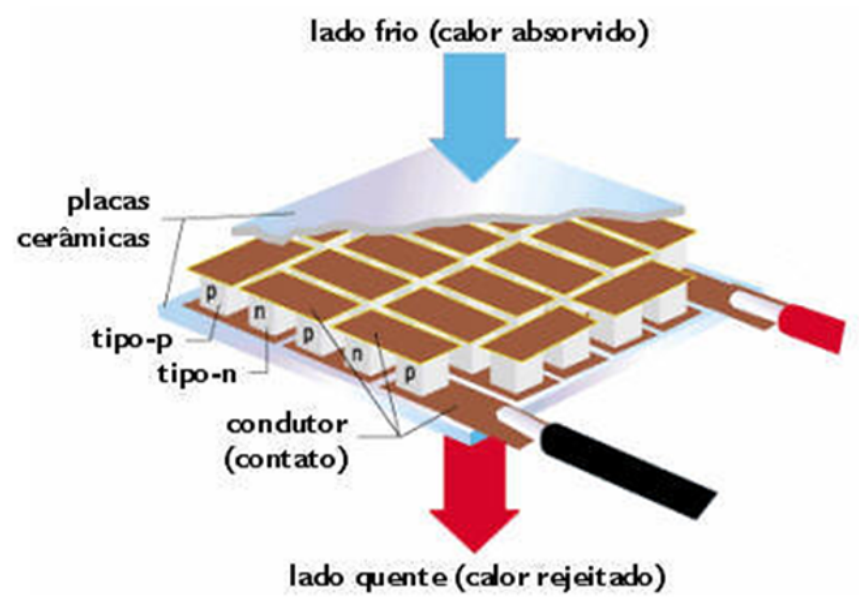

Figura 2: Funcionamento da pastilha peltier. Fonte: FERNANDES, 2010.

- Demais conceitos e fenômenos que podem ser apresentados e compreendidos

No âmbito da Física, podemos destacar os conceitos de semicondutores, calor, temperatura, formas de transferência de calor, equilíbrio térmico, capacidade térmica e calor específico, condutores e isolantes térmicos, voltagem, corrente elétrica, corrente contínua, corrente alternada, potência elétrica, resistência elétrica e resistores. A atenção às unidades de medida também pode auxiliar bastante no aprendizado. A construção de gráficos, como os da evolução temporal da temperatura, também é fundamental para qualquer estudante de ensino médio.

\section{METODOLOGIA}

O material utilizado para a construção da mini geladeira pode ser: caixa de isopor de 3 litros de capacidade, revestida com papel alumínio (Figura 3), suporte de madeira isolante rígido (Figura 4), dissipadores de computador (Figura 5) e a pastilha peltier (Figura 6). Esta pastilha pode ser encontrada facilmente na internet por um preço bastante acessível, principalmente se comprada em maior quantidade, bem como em lojas de refrigeração que trabalhem com bebedouros que as utilizem. Também foram usados ventoinhas (coolers) retirados de computadores antigos e uma fonte desktop para ligar todo o sistema. 


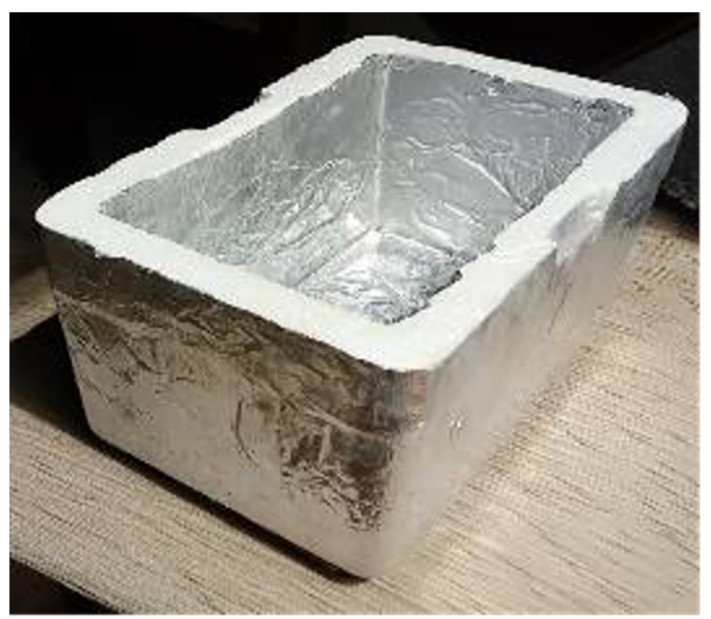

Figura 3: caixa de isopor revestida com papel aluminio.

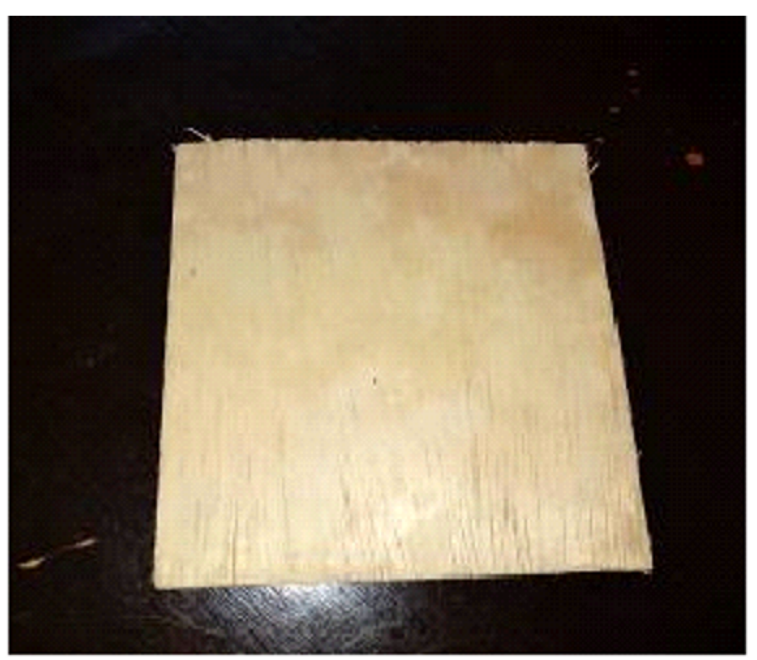

Figura 4: Pedaço de madeira (compensado).

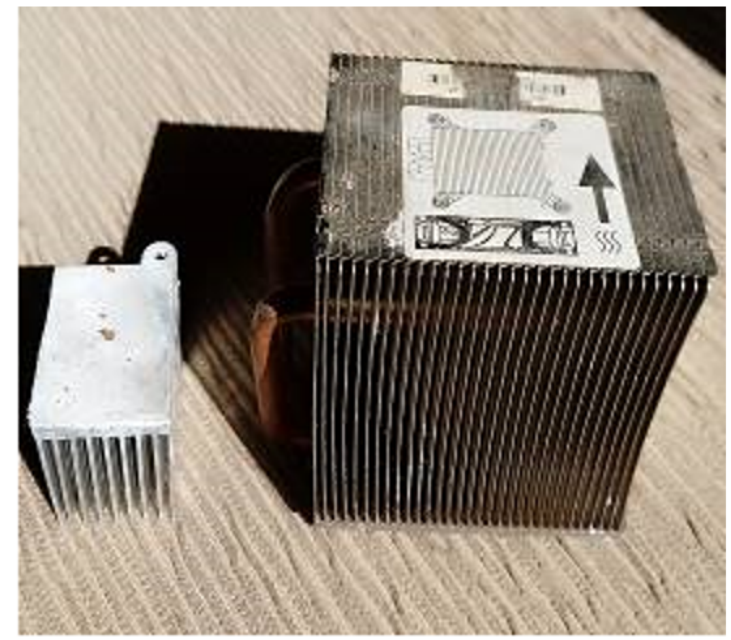

Figura 5: Dissipadores de calor (obtidos de computadores antigos). 


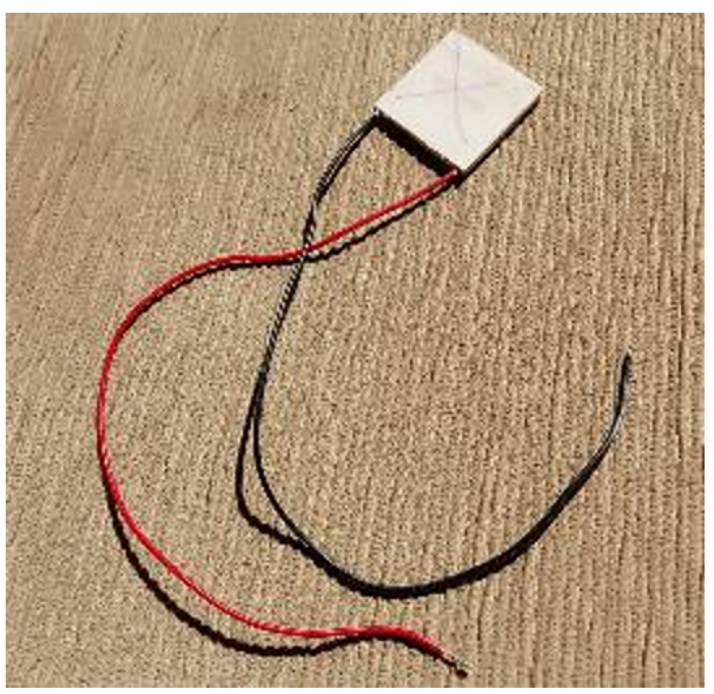

Figura 6: Pastilha peltier.

Iniciou-se então fazendo um buraco do tamanho da pastilha no centro do compensado, de maneira que ao inserir a pastilha, esta ficasse acessível a ambos os lados do compensado e abriu-se duas "trilhas" no extremo do buraco para se passar os fios. Essa estrutura foi adaptada em cima da tampa da caixa de isopor com o lado quente da pastilha para cima (Figura 7). No passo seguinte foi feito na tampa da caixa um buraco do mesmo tamanho do dissipador pequeno, esse dissipador ficaria em contato com a parte fria da pastilha e o ambiente interno da caixa (Figura 8). Esse dissipador ficou localizado dentro da caixa e foi adaptado por meio de parafusos no compensado, de maneira que a base do dissipador ficasse visivelmente para fora para se adaptar à parte externa do sistema. Além disso, foi fixado um pequeno cooler para circular o ar frio (Figuras 9 e 10).

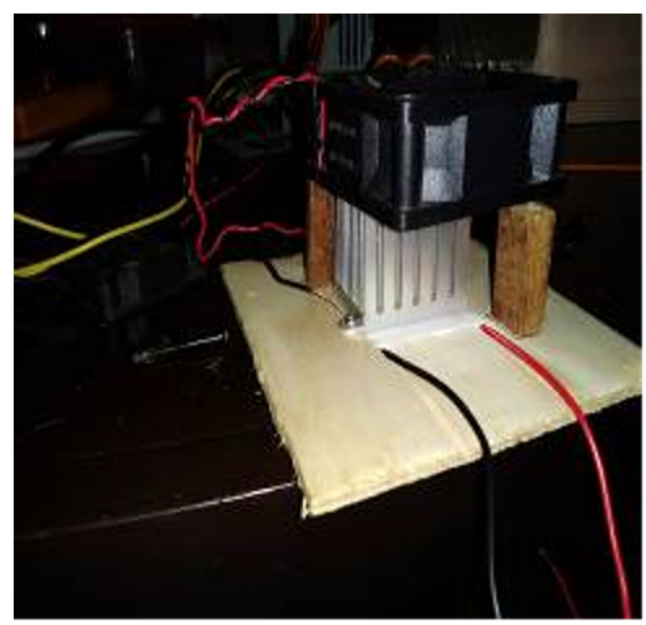

Figura 7: Estrutura do lado interno da caixa térmica. 


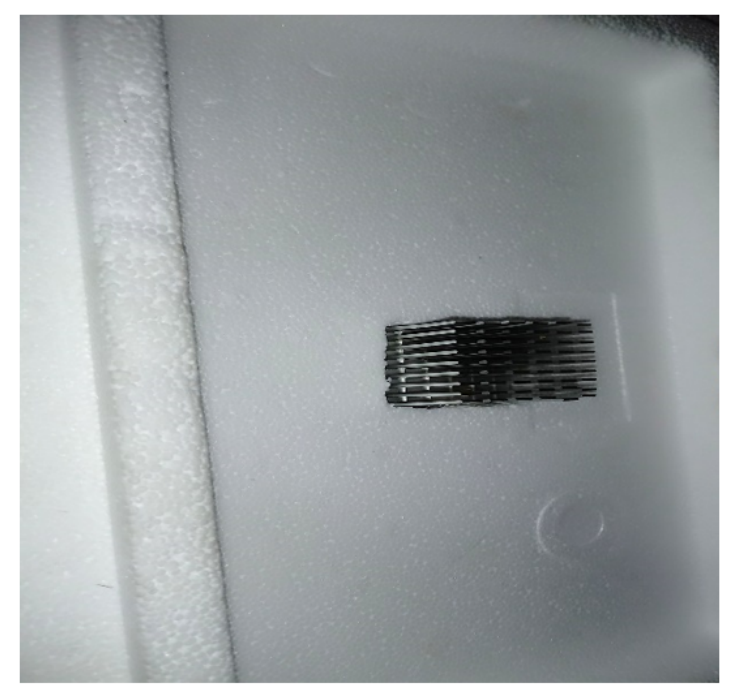

Figura 8: Furo no centro da tampa da caixa para passagem do dissipador.

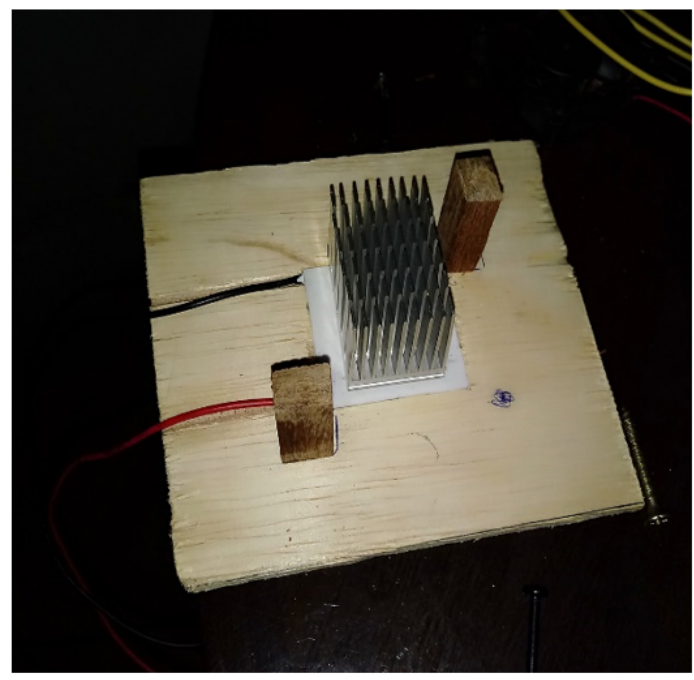

Figura 9: Pré-montagem do sistema de refrigeração interno, com adaptação do dissipador e cooler. 


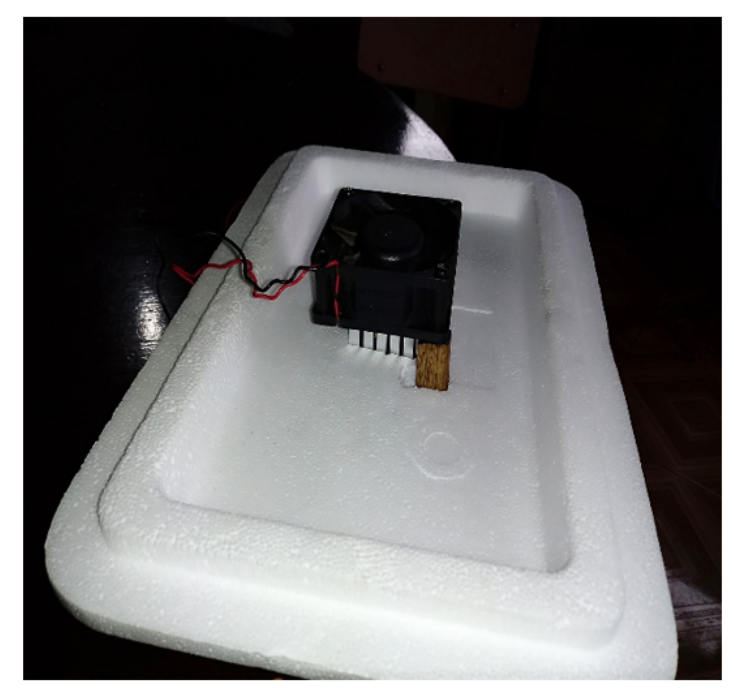

Figura 10: Montagem final do sistema de refrigeração interno.

Foi inserida pasta térmica na pastilha e também no dissipador/cooler maior que seria posto em cima do lado quente (externo). A expectativa era que esse dissipador retirasse o máximo de calor da pastilha para que a outra face resfriasse (Figura 11). O arranjo final do lado externo ficou conforme a Figura 12.

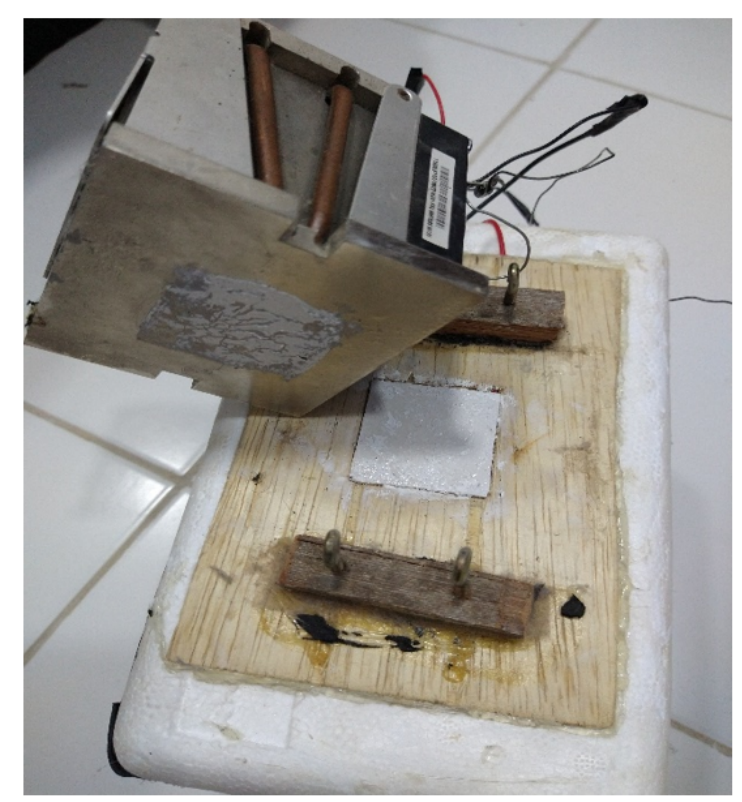

Figura 11: Arranjo final do dissipador/cooler externo junto à pastilha. 


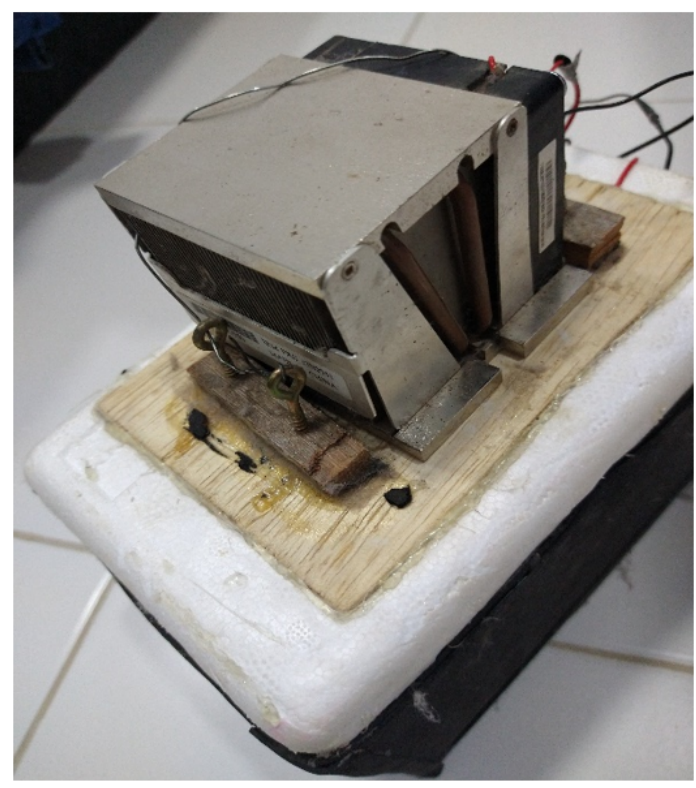

Figura 12: Tabuleiro Montado e Maquetes.

Para o protótipo final, revestiu-se toda a estrutura externa da caixa com duas camadas de papel E.V.A., utilizando cola quente para fixar, o termômetro foi fixado na lateral da caixa. Foram feitas algumas adaptações na tampa, foram colados dois pedaços pequenos de madeira no compensado, e nesses dois pedaços de madeira utilizei dois parafusos de argola, com o intuito de prender e apertar o dissipador contra a pastilha. A montagem final ficou da forma indicada na figura 13:

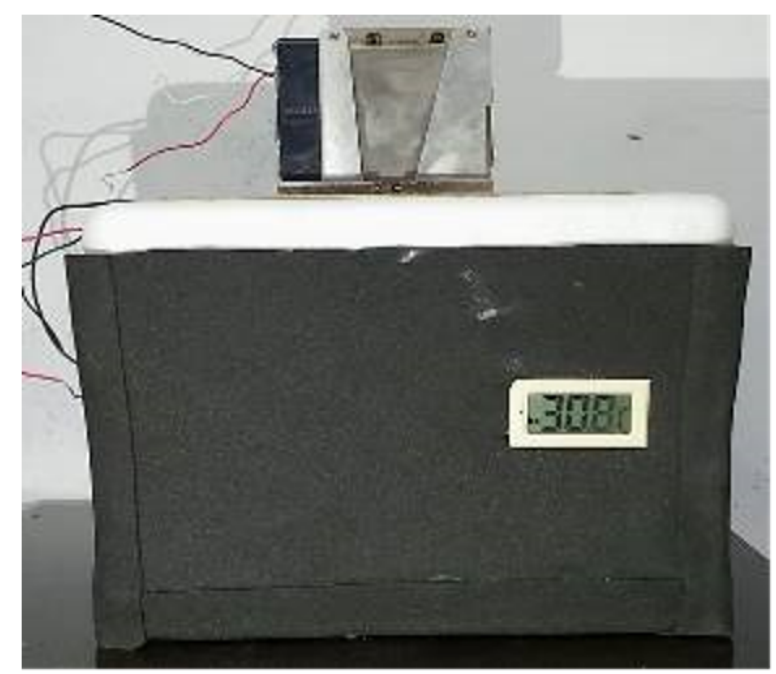

Figura 13: Protótipo final da mini-geladeira.

Para melhorar a estética da fonte de energia (ATX), foi construída uma fonte de bancada (Figura 14), eliminando todo o excesso de fio e padronizando as entradas e saídas de energia. O detalhamento da construção desta fonte não será feito neste artigo. 


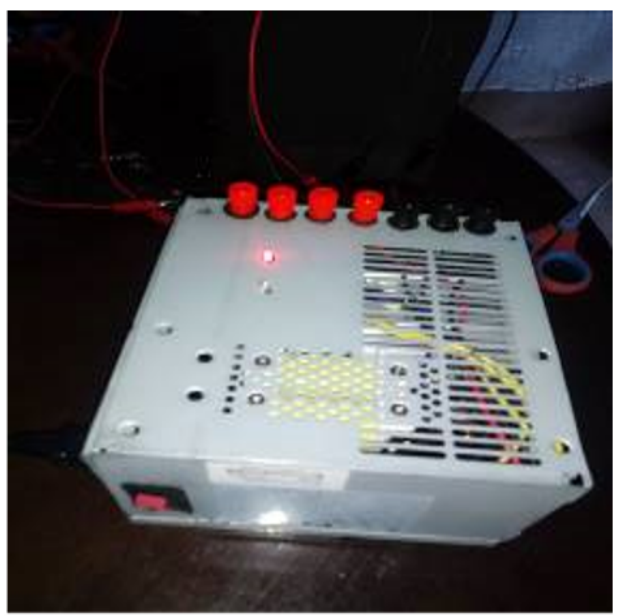

Figura 14: Fonte de bancada. Útil não somente neste caso, mas para qualquer experimento que seja preciso fontes de corrente continua.

\section{RESULTADOS E DISCUSSÕES}

Neste tópico será avaliado o funcionamento da mini-geladeira, o comportamento dela em vários valores de temperatura ambiente, que serão analisadas em forma de gráficos, bem como a construção e funcionamento desta pode auxiliar no processo de ensino/aprendizagem de alguns conceitos físicos. Ao final, poderemos criar possíveis questionamentos que podem ser feitos aos alunos nesse processo.

Após os testes realizados foram obtidos os resultados com a mini-geladeira vazia, o que resultou no gráfico mostrado na figura 15.

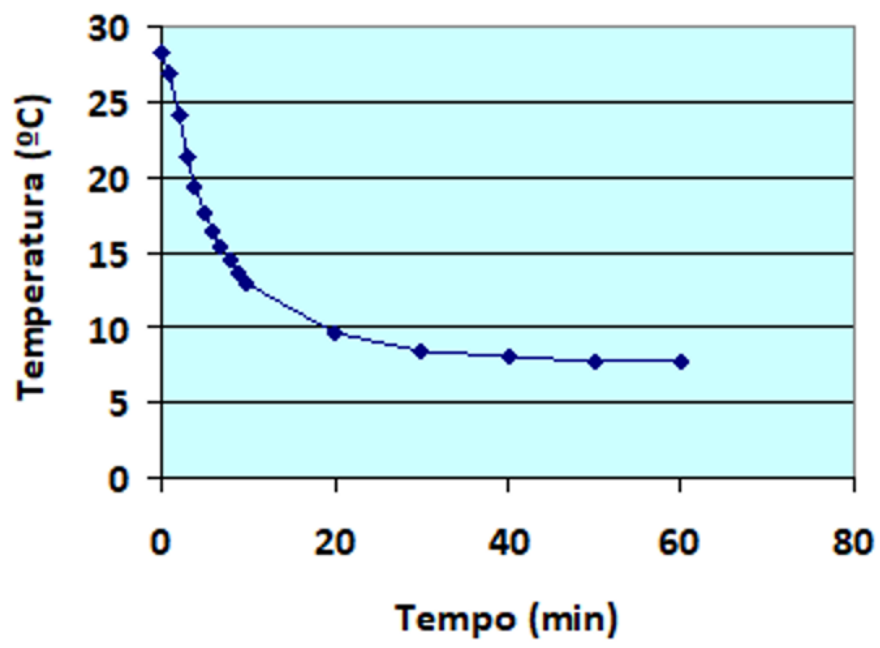

Figura 15: Série temporal da temperatura interna da mini-geladeira (vazia) - primeiro protótipo.

Pode-se perceber que a temperatura caiu consideravelmente. Ao ligá-la, a temperatura ambiente estava em torno de $28,2^{\circ} \mathrm{C}$, e nos dois primeiros minutos, a temperatura já estava em $24,1^{\circ} \mathrm{C}$, em cinco minutos, $17,6^{\circ} \mathrm{C}$. Observa-se que nos primeiros cinco minutos a 
temperatura já tinha caído cerca de $10,6^{\circ} \mathrm{C}$. Chegando aos 10 minutos de funcionamento, a temperatura ambiente da mini-geladeira já estava em $13,0^{\circ} \mathrm{C}$. A partir daí ela já começava a diminuir mais lentamente e em 40 minutos, $8,1^{\circ} \mathrm{C}$. Nesse momento a temperatura já começava a se estabilizar. Nos 20 minutos seguintes, a temperatura se manteve estável em $7,8{ }^{\circ} \mathrm{C}$. Em uma hora de funcionamento conseguiu-se diminuir em $20,4{ }^{\circ} \mathrm{C}$ a temperatura ambiente.

Para o último teste, foi colocado dentro da mini-geladeira, uma lata de refrigerante com $100 \mathrm{ml}$ de água, e os resultados obtidos, com o termômetro dentro da água, são mostrados na figura 16.

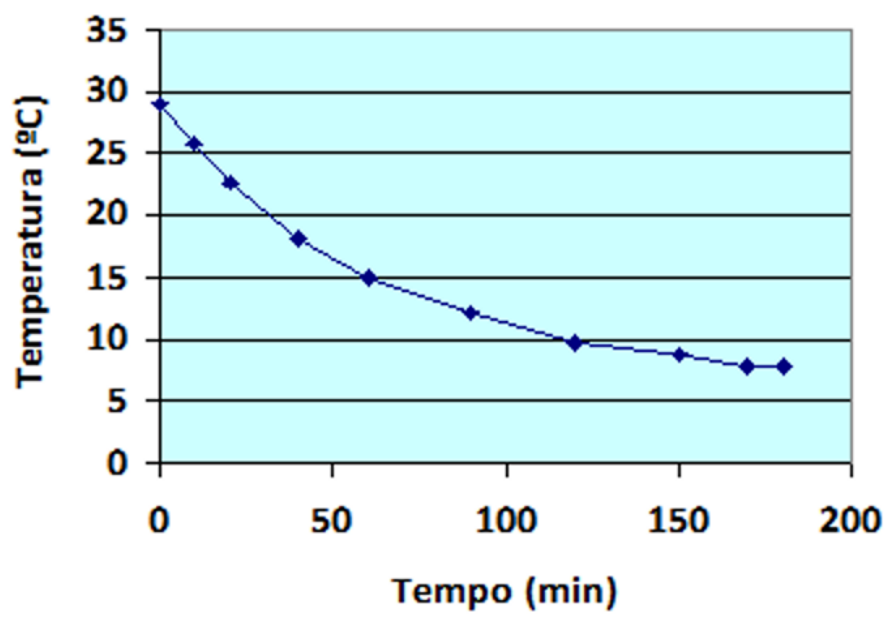

Figura 16: Série temporal da temperatura de $100 \mathrm{ml}$ de água colocados na mini-geladeira.

Observamos, por meio deste gráfico, que houve uma maior demora para se estabilizar a temperatura, o que era esperado. Quando foi ligada a mini-geladeira, a temperatura da água estava em torno de $29,1^{\circ} \mathrm{C}$, nos 10 primeiros minutos caiu para $25,8^{\circ} \mathrm{C}$, em 30 minutos estava em $20^{\circ} \mathrm{C}$. Completando quase as 3 horas de funcionamento a temperatura da água se estabilizou em $7,8^{\circ} \mathrm{C}$. Mesmo com uma carga térmica razoável em seu interior, a mini-geladeira se mostrou apta a fornecer um resfriamento considerável, a ponto de ser utilizável para fins cotidianos.

Durante o processo de construção e funcionamento da mini-geladeira, é notório que se pode trabalhar diversos conceitos físicos. Algumas perguntas podem ser feitas aos alunos, de maneira a aguçar sua curiosidade, levando-o a pesquisar (caso não saiba responder no momento) para respondê-las, motivando a busca pela compreensão de determinados conceitos. Alguns questionamentos propostos podem ser:

- Por que se precisa de uma fonte de corrente contínua para ligar o sistema? Qual a diferença entre corrente contínua e alternada?

- Por que se preocupar com as especificações da fonte? Por que não podemos ligar a pastilha em qualquer voltagem?

- Por que a mini-geladeira foi construída em uma caixa de isopor? 
- Por que revestir a caixa de isopor com papel alumínio?

- Por que o uso do papel E.V.A.?

- Por que o uso da pasta térmica? Do que ela é feita?

- Por que após colocar um recipiente com água dentro da mini-geladeira a temperatura diminui mais lentamente?

- Por que a pastilha peltier esfria um lado e esquenta o outro?

- Por que é necessário um dissipador/cooler instalado no lado quente da pastilha peltier?

- Por que o dissipador é todo "fatiado", e não inteiriço?

\section{Considerações Finais}

Ao desenvolver este trabalho, foi possível compreender como a educação pode sofrer impactos positivos quando associada à novas tendências ou metodologias que podem ser inseridas no contexto escolar, principalmente quando a disciplina em pauta é a de Física, que é muitas vezes temida por alunos. Neste caso, a mini-geladeira, possibilita ao aluno, o entendimento de diversos conceitos físicos no momento de sua construção e seu funcionamento.

Na construção da mini-geladeira, vários questionamentos podem ser levantados pelo professor, a fim de que ocorra o aprendizado paulatino e focado no protagonismo do aluno, que se forçará a buscar conceitos para responder.

\section{REFERÊNCIAS}

ALVES FILHO P. J. Atividades Experimentais: do Método à Prática Construtivista. 302 f. Tese (Doutorado em Educação: Ensino de Ciências Naturais) - Universidade Federal de Santa Catarina, 2000.

DANVIC. Pastilha de efeito peltier, c2020. Disponível em <http:/ /www.danvic.com/produtos/pastilhade-efeito-peltier/>

FERNANDES, J. D. F. S.; BRAZ, A. F.; MACHADO, L. S. S. X.; PIMENTEL, E . S.; FARIAS, A. V. A.; CAMPOS, A. L. P. S. Refriferação utilizando pastilhas de efeito peltier. Holos. V.2, p. 25-31. 2010

HALVERSON, E. R.; SHERIDAN, K. M.; BRAHMS, L.; LITTS, B. K.; JACOBS-PRIEBE, L.; OWENS, T. Learning in the making: A comparative case study of three makerspaces. Harvard Educational Review, v. 4, n. 84, 505-531, 2014. 
MONTEIRO, P. P.; SENA, A. J. Sistema de resfriamento de equipamentos industriais utilizando células peltier. INOVA TEC: A Revista Eletrônica da Estácio Belém, v. 1, Belém, 2016.

NONAKA, I.; TAKEUCHI, H. Criação do Conhecimento na Empresa: como as empresas geram a dinâmica da inovação. Rio de Janeiro: Campus,1997.

PAPERT, S. Mindstorms: Children, computers and powerful ideas. Basic Books, inc. Artes Médicas: Porto Alegre. 1980.

SILVEIRA, F. Design E Educação: novas abordagens. In: MEGIDO, V. F. (Org.). A Revolução do Design: conexões para o século XXI. São Paulo: Editora Gente, 2016, p. 116-131. 